\title{
CARACTERIZAÇÃO ATMOSFÉRICA QUANDO DA OCORRÊNCIA DE EVENTOS EXTREMOS DE CHUVA NA REGIÃO SUL DE MINAS GERAIS
}

\author{
REBOITA,Michelle Simões - reboita@unifei.edu.br \\ Universidade Federal de Itajubá / UNIFEI
}
MARIETTO, Diogo Malagutti Gonçalves - diogomarietto18@gmail.com Universidade Federal de Itajubá / UNIFEI

SOUZA,Amanda - amanda.cs.ig@hotmail.com

Universidade Federal de Itajubá / UNIFEI

BARBOSA, Marina - barbosa.marinaalmeida@gmail.com Universidade Federal de Itajubá / UNIFEI

\begin{abstract}
RESUMO: O objetivo deste estudo é apresentar uma descrição das características da atmosfera que contribuíram para elevados totais de precipitação no sul de Minas Gerais e que foram precursores de dois episódios de inundação e alagamento na cidade de Itajubá: um em 16 de janeiro de 1991 e outro em 02 de janeiro de 2000. Para tanto, foram utilizados dados do Climate Prediction Center e da reanálise ERA-Interim do European Centre for Medium-Range Weather Forecasts (ECMWF). Entre os resultados, têm-se que os episódios de inundação e alagamento ocorridos na cidade de Itajubá, em ambos os anos, estiveram associados à atuação da Zona de Convergência do Atlântico Sul, que se estendia da Amazônia, passando pelo sudeste do Brasil, e chegava ao Atlântico Sul.
\end{abstract}

Palavras- chaves: Inundações, Eventos Extremos de Precipitação, Sul de Minas Gerais

ATMOSPHERIC CHARACTERIZATION DURING PRECIPITATION EXTREME EVENTS OVER SOUTHERN MINAS GERAIS STATE

ABSTRACT: The purpose of this study is to present a description of the atmosphere features, which contributed to large values of rainfall in southern Minas Gerais State and were precursors of two flooding events in Itajubá: one on January 16, 1991 and the other on January 02, 2000. For this reason, data from Climate Prediction Center and the ERA-Interim reanalysis of the European Centre for Medium-Range Weather Forecasts (ECMWF) were used. Among the results, we show that the flooding events in Itajubá, in both years, were associated with the South Atlantic Convergence Zone that extended from Amazon region to the South Atlantic Ocean, and passed over southestern Brazil.

Keywords: Flooding, Precipitation Extreme Events, Southern Minas Gerais State.

\section{INTRODUÇÃO}

O Painel Intergovernamental de Mudanças Climáticas (IPCC, 2007, 2013) define como evento extremo os fenômenos atmosféricos que são raros de ocorrer num determinado local; exemplo: um total diário de precipitação que é maior do que o percentil de $90 \%$ da série histórica de uma dada localidade. Associados aos eventos extremos chuvosos têm-se as enchentes, as inundações e os alagamentos. Segundo Amaral e Gutjahr (2012), as enchentes correspondem à elevação do nível d'água de um canal até atingir a sua cota máxima. Quando a água ultrapassa esse limite tem-se a inundação. Já os 
alagamentos ocorrem devido ao acúmulo de água por deficiência do sistema de drenagem. Nas cidades, em geral, pessoas com baixa renda habitam áreas inapropriadas nas cercanias de corpos hídricos; dessa forma, podem sofrer com a ocorrência de inundações e alagamentos. Moradores de outras áreas urbanas também estão expostos às consequências negativas dos eventos extremos chuvosos, se a drenagem da superfície não for suficiente para escoar a água da chuva.

A região sul de Minas Gerais, entre a primavera e o outono, é susceptível à ocorrência de eventos extremos de chuva, pois faz parte da região do país afetada pelo Sistema de Monção da América do Sul - SMAS (VERA et al., 2006; REBOITA et al., 2010; MARENGO et al., 2012; SILVA e REBOITA, 2013). A definição clássica de monção corresponde à inversão sazonal do sentido dos ventos entre dois períodos do ano, o que vai caracterizar um período seco e um chuvoso. Na estação chuvosa, os ventos se dirigem do oceano para o continente. Na América do Sul, a inversão dos ventos só é observada quando a média anual das componentes do vento é removida da média sazonal (REBOITA et al., 2012a).

A estação chuvosa, na região que se estende do oeste da Amazônia até o Estado de São Paulo e centro-sul de Minas Gerais, é caracterizada pela ocorrência de diferentes sistemas atmosféricos que constituem o SMAS. Esses sistemas são: o jato de baixos níveis a leste dos Andes (JBN; MARENGO et al., 2004), a convecção na Amazônia e a Alta da Bolívia - AB (ZHOU e LAU, 1998), o cavado em altos níveis nas cercanias do nordeste do Brasil e o transporte de umidade pelos ventos do setor oeste do Anticiclone Subtropical do Atlântico Sul - ASAS (REBOITA et al., 2010). A junção desses sistemas contribui para a formação da Zona de Convergência do Atlântico Sul (ZCAS), que pode ser caracterizada por uma banda de nebulosidade, vista em imagens de satélite, se estendendo da Amazônia, passando pelo sudeste do Brasil e chegando ao oceano Atlântico Sudoeste (KOUSKY, 1988; CARVALHO et al., 2004). Portanto, a ZCAS se estabelece onde há convergência de umidade em baixos níveis da troposfera (NOGUÉS-PAEGLE e MO, 1997). Na ocorrência da ZCAS, também se pode observar uma frente fria semi-estacionária sobre o sudeste do Brasil ou próxima a essa região (OLIVEIRA, 1986; REBOITA et al., 2010). Episódios de ZCAS têm uma duração mínima de quatro dias, podendo persistirem por até dez dias ou mais (SACRAMENTO-NETO et al., 2010). Segundo Lima et al. (2010), $47 \%$ da precipitação na região sudeste, na estação chuvosa (verão), deve-se a episódios de ZCAS. Como a ZCAS é um sistema persistente, pode contribuir para ocorrência de enchentes, inundações e alagamentos. Também por efeito das chuvas, podem ocorrer deslizamentos de terra, assim como outros desastres naturais.

Seluchi e Chou (2009) elaboraram uma climatologia sinótica para caracterizar a atmosfera quando da ocorrência de chuvas na Serra do Mar que propiciaram deslizamentos de terra entre novembro a abril dos anos de 1995 a 2005. Para isso, foi utilizada a reanálise 1 do National Centers for Environmental Prediction (NCEP-NCAR; KALNAY et al., 1996) e elaborados mapas de composições (médias) no período de três dias antes a dois dias após os eventos de deslizamentos. Os resultados indicam que os deslizamentos de terra estão associados à ocorrência de frentes frias e ZCAS. 
Entre os 33 eventos de deslizamentos de terra abordados por Seluchi e Chou (2009), provavelmente, um se encontra associado à precipitação extrema ocorrida na primeira semana de janeiro de 2000. Sugahara et al. (2010) documentaram esse caso de evento extremo de precipitação considerando o Vale do Paraíba na parte leste do Estado de São Paulo. Segundo os autores, o evento extremo, que foi registrado nas dez estações meteorológicas selecionadas para o estudo, pode ser classificado como extremamente raro para a região. Esse evento extremo de precipitação também causou impactos socioeconômicos no sul do Estado de Minas Gerais. Por exemplo, na cidade de Itajubá ( $22^{\circ} 25^{\prime} 32^{\prime \prime S}, 4^{\circ} 27^{\prime} 10^{\prime \prime} \mathrm{W}$ ) ocorreram inundações e alagamentos, como mostra a Figura 1. Segundo um Relatório Técnico (2000), esse episódio atingiu $80 \%$ da população itajubense. Outro evento extremo de precipitação que causou impactos em Itajubá foi o ocorrido em 16 de janeiro de 1991. Uma cronologia das inundações ocorridas em Itajubá entre 1819 e 2014 é apresentada em Barbosa et al. (2015).

Diante do exposto, o objetivo do presente estudo é descrever as características da atmosfera durante os dois casos de inundações e alagamentos citados na cidade de Itajubá (1991 e 2000). Além disso, pretende-se verificar se há semelhança nos padrões de ambos os eventos

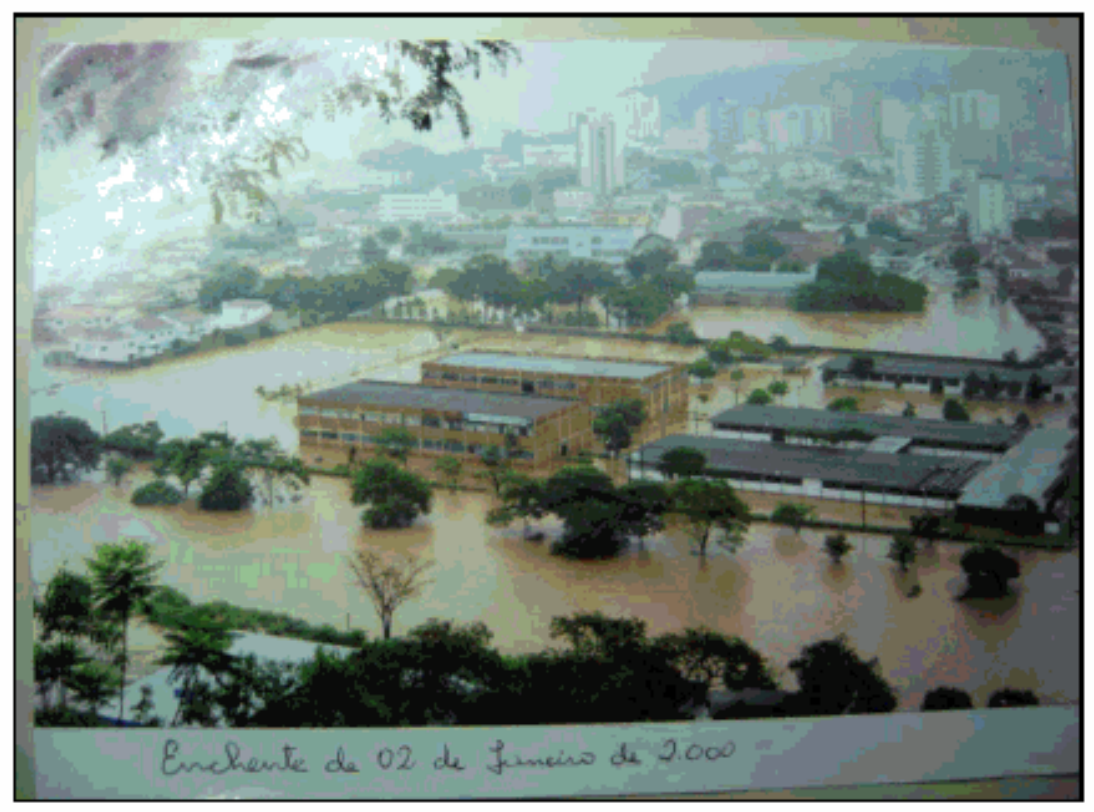

Figura 1 - Alagamento registrado no dia 02/01/2000 na Av. Dr. Antônio Braga Filho Marginal Direita Conjunto Universitário da FEPI, cota do terreno 842,70 m, nível de cheia: $100 \mathrm{~cm}$, cota da cheia: 843,70 m. Fonte: Prefeitura Municipal de Itajubá - MG (http://www.itajuba.mg.gov.br/).

\section{MATERIAIS E MÉTODOS}

\section{1 ÁREA DE ESTUDO}

O município de Itajubá localiza-se nas encostas da Serra da Mantiqueira, no sul do Estado de Minas Gerais, ocupando uma área de 290,45 km² de extensão. De acordo com a prefeitura municipal (http://www.itajuba.mg.gov.br/ 
cidade/localizacao.php), a sede de Itajubá situa-se nas coordenadas geográficas $22^{\circ} 30^{\prime} 30^{\prime \prime} \mathrm{S}$ e $45^{\circ} 27^{\prime} 20^{\prime \prime} \mathrm{O}$ e numa altitude média de $842 \mathrm{~m}$. Como esse município localiza-se no sudeste do Brasil, seu clima é regido pelo SMAS (REBOITA et al., 2012a; SILVA e REBOITA, 2013). Conforme a classificação climática de Köppen, o clima de Itajubá é o Cwa, isto é, clima temperado úmido com inverno seco e verão quente (REBOITA et al., 2013). A maior temperatura média é de $23,3^{\circ} \mathrm{C}$ em fevereiro e a menor é de $15,1^{\circ} \mathrm{C}$ em julho. Já o total médio anual de precipitação é de $1458 \mathrm{~mm}$, com cerca de $80 \%$ desse valor ocorrendo de outubro a março (REBOITA et al., 2016).

Ainda de acordo com a prefeitura municipal, a topografia de Itajubá é do tipo ondulada-montanhosa e a ocupação do solo está distribuída em 219,75 km² de área rural e em 70,70 km² de área urbana. Com relação à área de estudo, é importante destacar a influência do rio Sapucaí (que divide a cidade de Itajubá em dois setores), pois as inundações e alagamentos nos anos de estudo estiveram associados ao trasbordamento desse rio, já que ele recebe águas de diferentes municípios do sul de Minas Gerais antes de passar por Itajubá (Fig. 2). Além disso, como o desenvolvimento da cidade de Itajubá foi ligado diretamente ao rio Sapucaí, grande parte da população se estabeleceu em suas margens (Fig. 3), de forma que a cidade cresceu ao redor do rio (http://www.cbhsapucai.org.br/). Santos (2013) comparou imagens de satélite dos anos de 2000 e 2011 para analisar conflitos da ocupação urbana em Itajubá e, entre os resultados, mostrou o aumento da ocupação indevida em alguns setores das margens do rio Sapucaí.

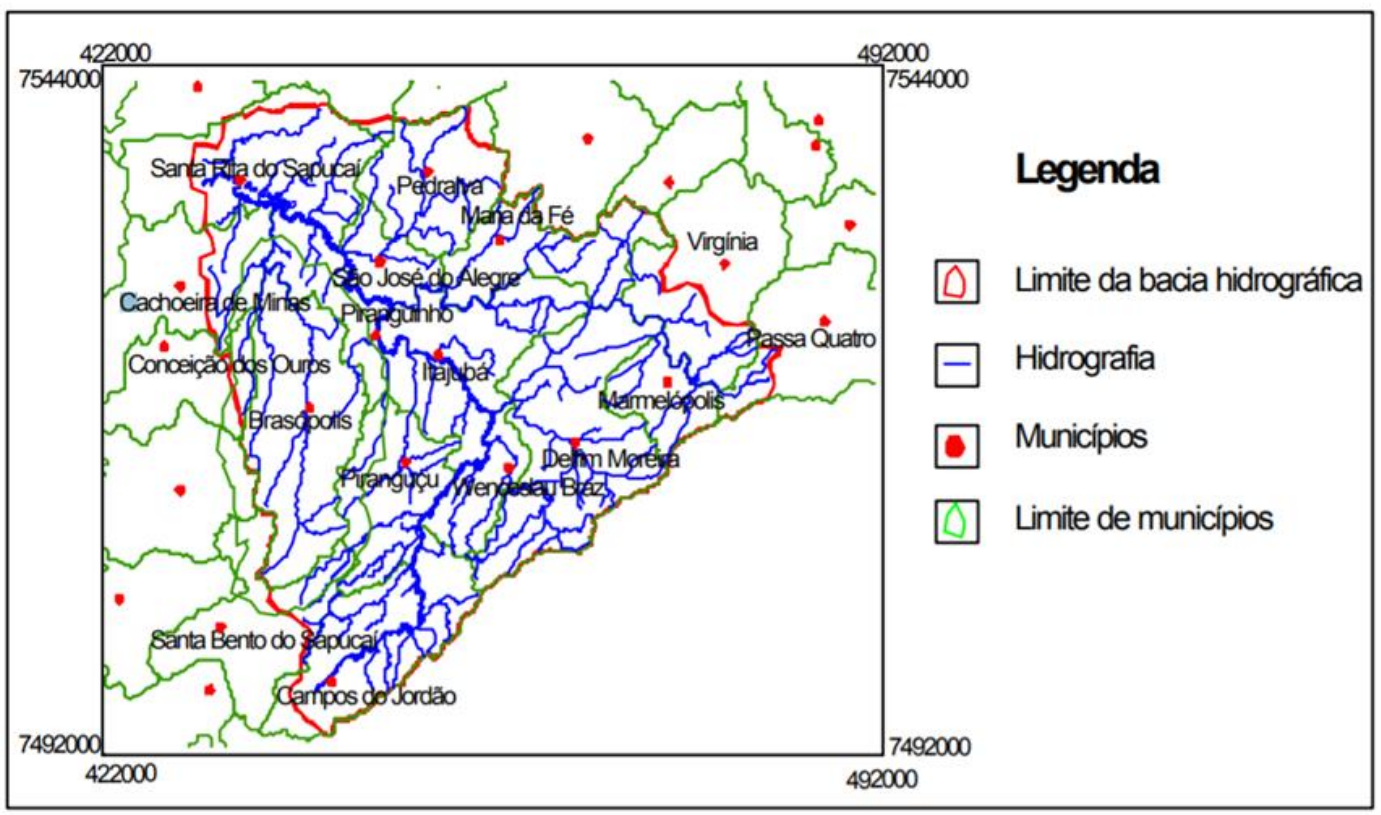

Figura 2 - Área da Bacia Hidrográfica do Alto Sapucaí. Fonte: Maia (2003). 


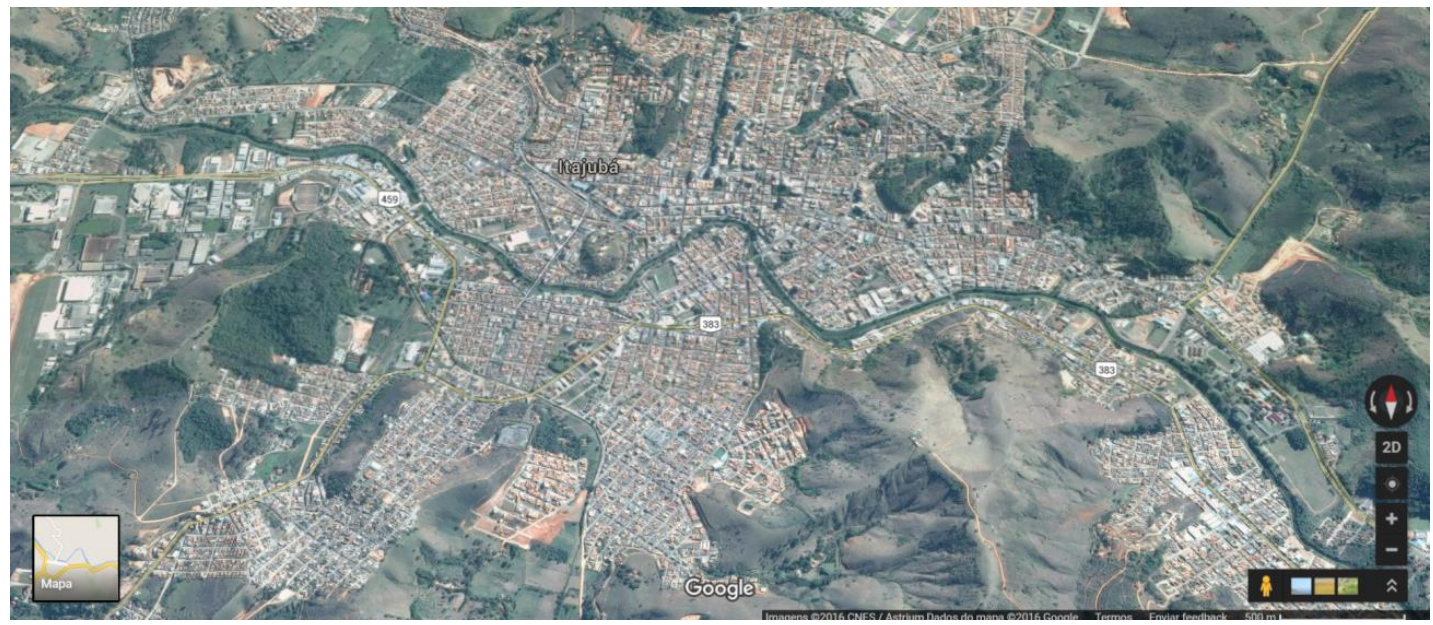

Figura 3 - Trecho do rio Sapucaí cruzando a cidade de Itajubá. Fonte: Google Maps, 1906-2016.

\subsection{DADOS E ANÁLISES}

Foram utilizados dados de diferentes fontes no presente estudo. Para fazer uma contextualização geral da disponibilidade de vapor d'água na atmosfera durante os dois episódios em estudo, obtiveram-se imagens combinadas dos satélites GOES e METEOSAT do canal vapor d'água (KNAPP et al., 2011) disponíveis em https://www.ncdc.noaa.gov/gibbs/year. As imagens e os demais dados descritos foram obtidos para os dias 15 a 17 de janeiro de 1991 e para os dias 01 a 03 de janeiro de 2000, isto é, são de um dia antes do evento de inundação, do dia do evento e de um dia após.

Dados diários de precipitação foram obtidos do Climate Prediction Center - CPC (SILVA et al., 2007, 2011; CHEN et al., 2008) com resolução horizontal de $0,25^{\circ} \times 0,25^{\circ}$ de latitude e longitude. O conjunto de dados do CPC é construído através da interpolação espacial de totais diários de precipitação medidos in situ. Os dados em pontos de grade cobrindo as superfícies continentais do globo são disponibilizados em ftp://ftp.cpc.ncep.noaa.gov/precip/CPC_UNI_PRCP/GAUGE_GLB/. Para se ter uma estimativa da umidade relativa do solo na camada $10-100 \mathrm{~cm}$ de profundidade, utilizaram-se as imagens geradas a partir de simulações numéricas de um modelo de superfície do projeto Latin America Flood and Drought

Monitor (http://stream.princeton.edu/LAFDM/WEBPAGE/index.php?locale=es).

As outras variáveis atmosféricas utilizadas no estudo (pressão ao nível médio do mar - PNMM, radiação de onda longa, altura geopotencial em 500 e $1000 \mathrm{hPa}$ e componentes zonal e meridional do vento nos níveis de 250 e 850 $\mathrm{hPa}$ ) foram obtidas da reanálise ERA-Interim (DEE et al., 2011; http://apps.ecmwf.int/datasets/data/interim-full-daily/levtype=pl/) com resolução horizontal de $0,75^{\circ} \times 0,75^{\circ}$ e intervalo de 6 horas para os mesmos períodos citados anteriormente. A reanálise utiliza dados observados por diferentes fontes e modelados para construir um conjunto de dados com espaçamento de grade uniforme sobre o globo. 
A altura geopotencial é usada como uma coordenada vertical na maioria dos estudos atmosféricos e é empregada em metros (WALLACE e HOBBS, 2006). Assim, a diferença de altura geopotencial entre duas superfícies de pressão atmosférica constantes (1000 e $500 \mathrm{hPa}$, por exemplo) fornece a distância entre as duas superfícies, o que também é chamado de espessura da camada. Quando a variação da espessura da camada é grande (linhas muito próximas) na horizontal, isso indica a ocorrência de intensos gradientes horizontais de temperatura do ar; portanto, é uma variável utilizada para a identificação de zonas frontais. No presente estudo, a espessura da camada foi computada entre 500 e $1000 \mathrm{hPa}$. Como o vento é uma grandeza vetorial, ele é formado por componentes. Com as componentes horizontais do vento, calculouse a divergência de massa (HOLTON, 2004). A divergência indica que há escoamento saindo de um determinado local para diferentes regiões/direções, enquanto que a convergência indica que o escoamento de diferentes regiões se dirige para um mesmo local. Convergência em baixos níveis da atmosfera é um elemento fundamental para a ascensão do ar e possível formação de nuvens (que ocorre se o ar que ascende possui umidade).

Com base nos dados descritos, foram elaborados mapas das variáveis atmosféricas entre os dias prévio e posterior à ocorrência das inundações e alagamentos em Itajubá que foram registrados nos dias 16 de janeiro de 1991 e 02 de janeiro de 2000, respectivamente. Isso permite uma análise da evolução dos sistemas atmosféricos na região de estudo e arredores. Para essa análise, utilizaram-se somente os dados das 18 UTC (que corresponde às 15 horas local, horário do máximo aquecimento diurno).

\section{RESULTADOS}

\subsection{AS CHUVAS EM 1991}

No evento de 1991, a inundação e o alagamento em Itajubá foram registrados no dia 16 de janeiro. Desde o dia 11 de janeiro, no nível de $850 \mathrm{hPa}$ (figuras não mostradas), o JBN está bem configurado se dirigindo da Amazônia para o sudeste do Brasil e há ocorrência de precipitação. Um dia antes do evento, o JBN continua se dirigindo da Amazônia para o sudeste do Brasil e chegando ao oceano Atlântico (Fig. 4a), onde converge com o escoamento do setor oeste do Anticiclone Subtropical do Atlântico Sul (ASAS) que não está mostrado por completo na Figura 4a. A precipitação se concentra ao longo da trajetória do JBN e excede $40 \mathrm{~mm}$ no sul de Minas Gerais (Fig. 4a). Em termos de PNMM, há um ciclone em $50^{\circ} \mathrm{S}$ e $40^{\circ} \mathrm{O}$ com um ramo frontal frio que se estende até o Uruguai. Já entre a costa sul-sudeste do Brasil há uma região de baixa pressão, com centro de 1005 hPa (Fig. 5a). Na mesma região em que há precipitação, ocorrem valores mais baixos de radiação de onda longa (Fig. 6a). Recorda-se que quando há nebulosidade, a radiação de onda longa não consegue sair da atmosfera terrestre e, portanto, os valores registrados são menores do que quando há condições de céu limpo. Com relação à alta troposfera, no nível de $250 \mathrm{hPa}$, a $\mathrm{AB}$ tem seu centro entre a costa oeste da América do Sul e a Bolívia (Fig. 6a). Os ventos no setor sul da $A B$ ajudam a acelerar 0 jato subtropical. Além disso, a sudeste da $A B$ forma-se uma crista entre a região sudeste do Brasil e o oceano, e associado a esse escoamento também se encontra um VCAN entre o litoral do nordeste brasileiro e o oceano Atlântico Tropical (Fig. 6a). Ainda considerando os altos níveis da atmosfera, 
nota-se na Figura 6d ocorrência de divergência de massa entre o Estado de São Paulo e sul de Minas Gerais, o que serve para sustentar os movimentos ascendentes na atmosfera e facilitar a formação de nuvens. A presença de nuvens na atmosfera também pode ser indicada através de imagens de satélite do canal vapor d'água. Na Figura $5 d$, nota-se que há muito vapor d'água na atmosfera numa banda entre as regiões norte, centro-oeste, sudeste e parte do nordeste do país e, também, entre o sudeste do Brasil e o oceano Atlântico. Essas áreas são as mesmas mostradas com elevados totais de precipitação e baixos valores de radiação de onda longa. A imagem de satélite também revela a posição do VCAN, já que, em geral, esse tipo de sistema possui centro seco e grande nebulosidade nos setores oeste e leste, como mostrado na Figura 5d.

No dia 16 de janeiro de 1991, dia do evento, o JBN começa a se desconfigurar (Fig. 4b), mas é o dia em que a precipitação no sul de Minas Gerais atinge os maiores totais diários desde o dia 11, isto é, mais de $60 \mathrm{~mm}$ (Fig. 4b). Embora o JBN se desconfigure, a região sul de Minas Gerais ainda recebe umidade do interior do continente, e a atividade convectiva, típica da estação de verão, favorece os movimentos ascendentes na atmosfera. A região de baixa pressão entre as costas das regiões sul-sudeste do Brasil se mantém estacionária enquanto que o sistema frontal teve deslocamento para nordeste, atuando no dia 16 de janeiro na divisa do Rio Grande do Sul com Santa Catarina (Fig. 5b). Nesse dia, o centro da $A B$ aparece na sua posição climatológica, e a crista sobre o sudeste do Brasil e o oceano se amplifica em relação ao dia anterior (Fig. 6b). De fato, sob a crista há convergência de massa e umidade (figura não mostrada) que favorecem os movimentos ascendentes na atmosfera e que forçam a alta troposfera, levando a maiores pressões; em outras palavras, formação de cristas (ou centros de alta pressão como no caso da $A B$ ). Já o VCAN continua bem configurado sobre o oceano Atlântico Tropical (Figs. 5b e 6b). Um dia após ao evento de inundação, o total diário de precipitação no sul de Minas Gerais é menor do que no dia prévio (Fig. 4c) e o centro de baixa pressão na costa sul-sudeste do Brasil se desconfigura, uma vez que a frente fria atinge o sudeste do Brasil (Fig. 5c). Já a circulação da $A B$ e VCAN se mantém. Durante os três dias em análise, a Figura $4 \mathrm{~d}-\mathrm{f}$ mostra que a umidade relativa do solo na camada entre 10 e $100 \mathrm{~cm}$ de profundidade foi de aproximadamente $100 \%$ em grande parte do sudeste do Brasil, incluindo o sul de Minas Gerais, o que sustentará a afirmação de que o solo encharcado é um dos motivos que contribuiu para os alagamentos na região em estudo.

Os padrões descritos das variáveis atmosféricas indicam a presença de um episódio de ZCAS. Esse sistema ocorre quando há concomitantemente a atuação de vários sistemas atmosféricos. Em baixos níveis da atmosfera há presença do JBN se dirigindo da Amazônia para o sudeste do Brasil, escoamento do setor oeste do ASAS em direção ao sudeste do país (que, em geral, converge com o JBN), convecção local e presença de baixa pressão entre a costa sul e sudeste do Brasil. Já em altos níveis da atmosfera tem-se a $A B$, o cavado em altos níveis nas cercanias do nordeste do Brasil e/ou do VCAN, uma crista entre o sudeste do Brasil e o oceano Atlântico e um cavado com eixo próximo ao sul do Brasil. Com essa configuração da atmosfera, a radiação de onda longa mostra baixos valores e a precipitação, totais elevados ao longo da trajetória do JBN. Segundo Sacramento Neto et al. (2010), esses padrões devem persistir por pelo menos 4 dias para caracterizar um episódio de ZCAS. Embora as variáveis 
atmosféricas nos dias prévios ao 15 não foram mostradas, desde o dia 11 de janeiro estavam configurados os padrões descritos
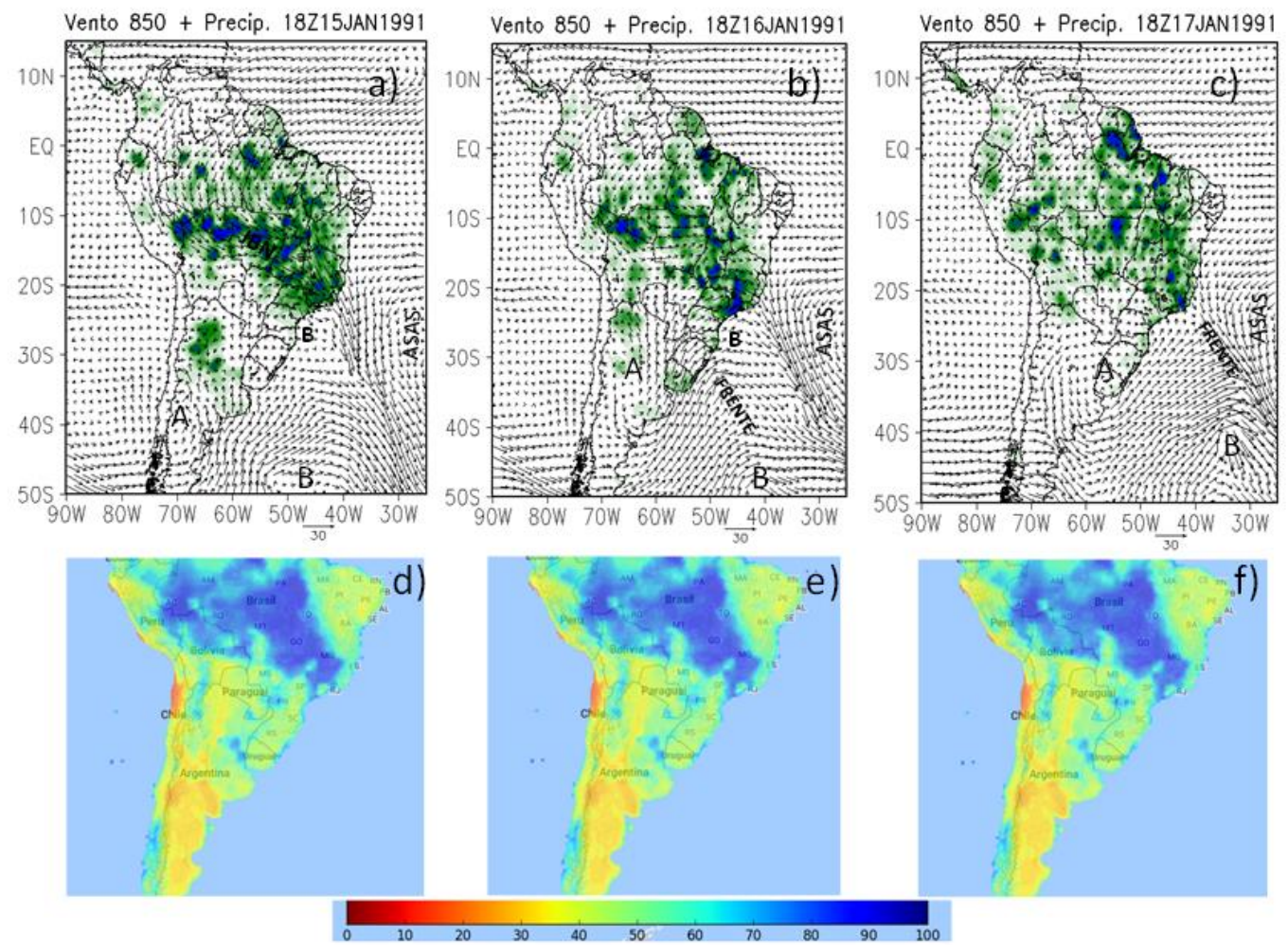

Figura 4 - (a-c) Total diário de precipitação ( $\mathrm{mm}$, colorido) e direção e intensidade do vento em $850 \mathrm{hPa}$ (vetores) e (d-f) umidade relativa (\%) do solo na camada entre $10 \mathrm{a}$ $100 \mathrm{~cm}$ de profundidade. As variáveis correspondem às 18 UTC (exceto a precipitação) desde um dia antes a um após ao alagamento registrado em Itajubá em 16 de janeiro de 1991. As figuras d-f foram obtidas de http://stream.princeton.edu/LAFDM/WEBPAGE/index.php?locale=es. Nas figuras, a letra B indica centro de baixa pressão, A centro de alta pressão, ASAS Anticiclone Subtropical do Atlântico Sul e FRENTE a posição de um sistema frontal.

Os estudos de Nogués-Paegle e Mo (1997) e Nogués-Paegle et al. (2001) sustentam a afirmação da presença de ZCAS no período de estudo, pois tanto o padrão da circulação em $850 \mathrm{hPa}$ quanto em $250 \mathrm{hPa}$ descritos concordam com os desses autores. Em Nogués-Paegle e Mo (1997) é mostrado que, para a ocorrência de ZCAS, o JBN deve se dirigir para o sudeste do Brasil, e não para o norte da Argentina e Rio Grande do Sul. Além disso, o ASAS não deve ter parte de seu centro sobre o sudeste do Brasil. Já Nogués-Paegle et al. (2001) mostram que, associada aos eventos de ZCAS, a circulação em altos níveis deve indicar a presença de um cavado nas cercanias da região sul do Brasil e de uma crista entre a região sudeste e o oceano Atlântico Sul. Com base no exposto, a inundação e o alagamento em Itajubá foram decorrentes do acúmulo de precipitação desde o dia 11 de janeiro de 1991, associado ao episódio de ZCAS, o que contribuiu tanto para um excesso de água no solo quanto para o 
extravasamento do rio Sapucaí, já que este e seus afluentes também receberam muita precipitação no período mencionado
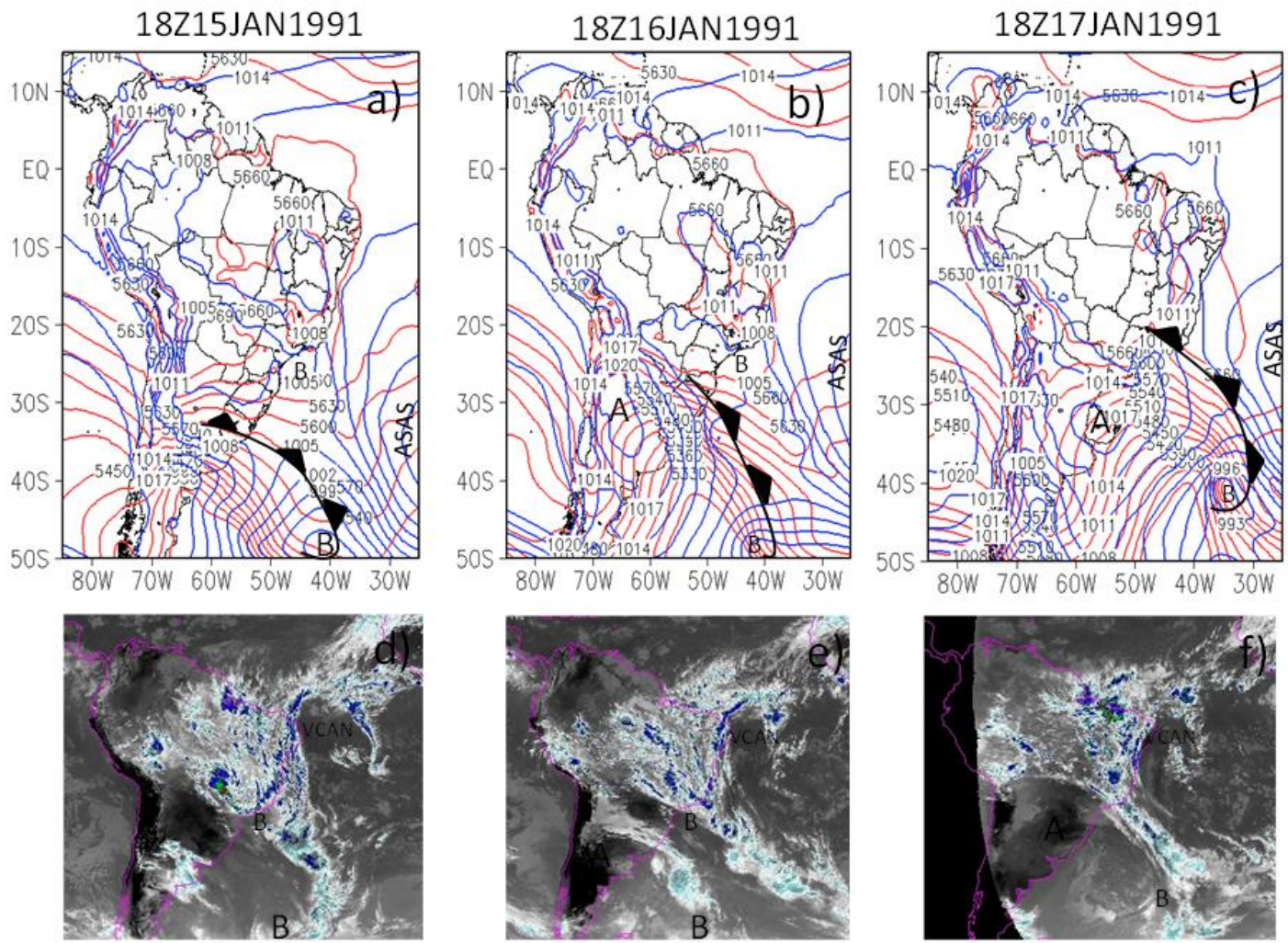

Figura 5 - (a-c) Pressão ao nível médio do mar (hPa, linha azul) e espessura da camada $500 / 1000 \mathrm{hPa}$ (metros, linha vermelha) e (d-f) vapor d'água na atmosfera (cores tendendo ao vermelho indicam maior quantidade de vapor d'água). Todas as figuras correspondem às 18 UTC desde um dia antes a um após ao alagamento registrado em Itajubá em 16 janeiro de 1991. As figuras (d-f) foram obtidas em https://www.ncdc.noaa.gov/gibbs/year. Nas figuras a letra B indica centro de baixa pressão, A centro de alta pressão, ASAS Anticiclone Subtropical do Atlântico Sul e a linha preta com triângulos a posição de um sistema frontal. 

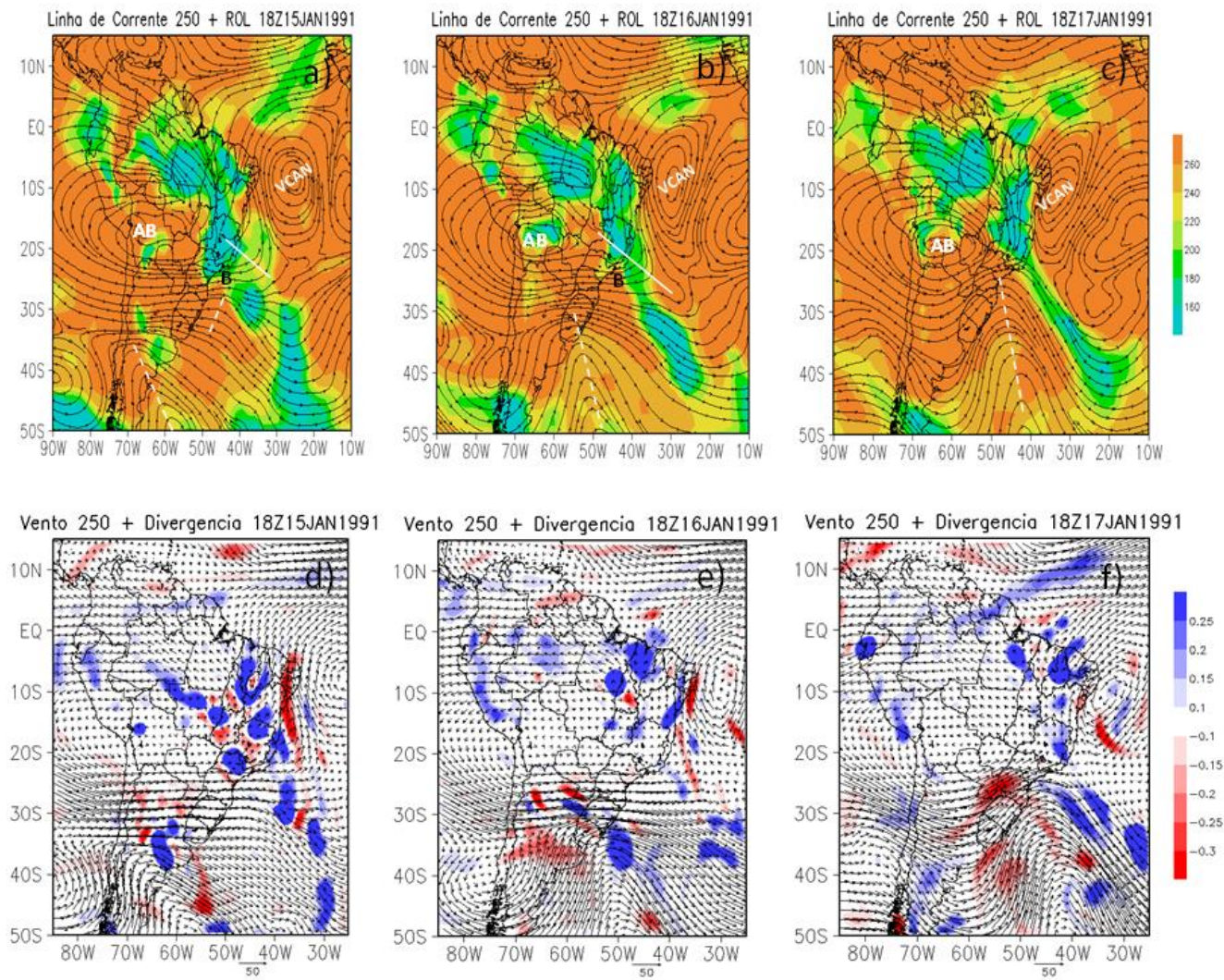

Figura 6 - (a-c) Radiação de onda longa (W/m2, colorido) e linhas de corrente em 250 $\mathrm{hPa}$ e (d-f) direção e intensidade do vento em $250 \mathrm{hPa}$ (setas) e divergência de massa em $250 \mathrm{hPa}$ (10-5s-1, colorido). Todas as figuras correspondem às 18 UTC desde um dia antes a um após ao alagamento registrado em Itajubá em 16 janeiro de 1991. Nas figuras, a letra B indica centro de baixa pressão em superfície. Já os demais símbolos indicam padrões em altos níveis sendo AB Alta da Bolívia, VCAN Vórtice Ciclônico de Altos Níveis nas Cercanias do Nordeste do Brasil, a linha branca tracejada indica o eixo de um cavado e linha branca contínua indica o eixo de uma crista.

\subsection{AS CHUVAS EM 2000}

No evento de 2000, a inundação e o alagamento foram registrados no dia 02 de janeiro. Nesse evento, a precipitação também foi decorrente da atuação de um evento de ZCAS. Desde o dia 29 de dezembro de 1999 é registrada precipitação no sul de Minas Gerais, porém os padrões atmosféricos que sustentam a ZCAS só se configuram a partir do dia 31 (figuras não mostradas). No dia anterior ao evento, o JBN está bem configurado com sentido da Amazônia para o sul de Minas Gerais, sendo que a precipitação registrada nessa última região foi superior a $50 \mathrm{~mm}$ (Fig. 7a). Além disso, a imagem de satélite também mostra o padrão clássico de ZCAS que é a presença de umidade numa banda estendendo-se da Amazônia, passando pelo sudeste do Brasil, e chegando ao oceano Atlântico Sul (Fig. 8d). No dia 01 de janeiro há um ciclone entre a costa sul-sudeste do Brasil e o oceano Atlântico Sul com pressão central de 1005 hPa (Fig. 8a). Como mostrado por Campetella e Vera (2002) e Reboita et al. (2012b), o JBN é modulado pela presença dos Andes e sistemas sinóticos transientes. Se o ciclone está entre a Argentina e o Uruguai, o JBN se dirige para essa região, se está na costa do Brasil, o jato desloca-se para tal local. 
Portanto, o ciclone tem importância na trajetória e intensidade do JBN que, por sua vez, é um transportador de umidade dos trópicos para os subtrópicos. A presença do ciclone bem configurado é um diferencial em relação ao evento de 1991. Outra diferença entre os eventos de 1991 e 2000 é que nesse segundo não há uma zona frontal se deslocando do sul da América do Sul em direção ao sudeste do Brasil (Fig. 8a-c). Por outro lado, o setor sudoeste do ASAS aparece estendido ao sul do ciclone atuando como um bloqueio ao deslocamento desse sistema (Fig. 8a-c). Essa situação sinótica com o ciclone sendo cercado pela alta pressão, de acordo com Escobar (2014), é o mais relevante na geração de episódios de chuvas anômalas sobre o Estado de Minas Gerais e está relacionado com a ocorrência de episódios de ZCAS.

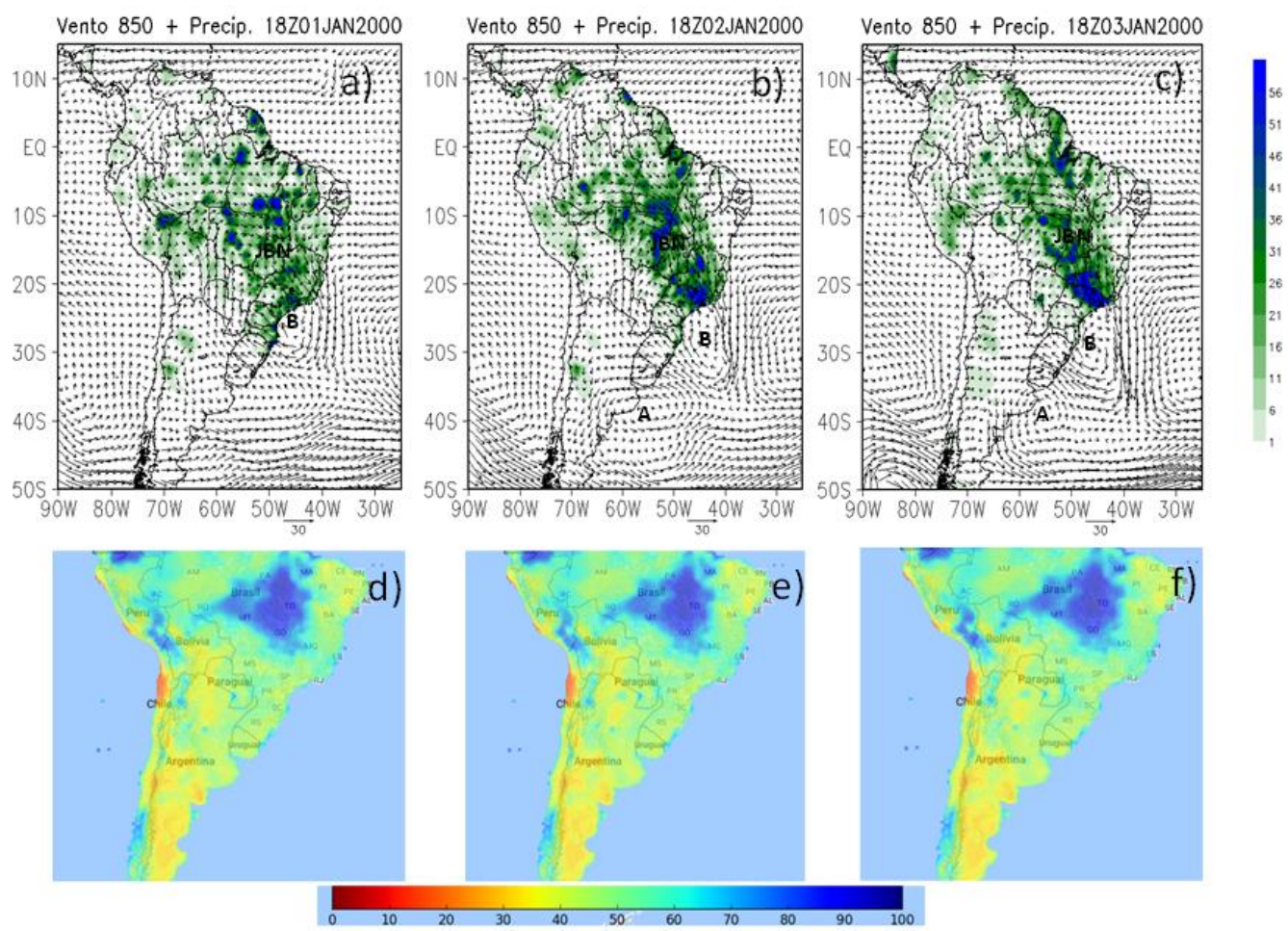

Figura 7 - (a-c) Pressão ao nível médio do mar ( $h P a$, linha azul) e espessura da camada $500 / 1000 \mathrm{hPa}$ (metros, linha vermelha) e (d-f) vapor d'água na atmosfera (cores tendendo ao vermelho indicam maior quantidade de vapor d'água). Todas as figuras correspondem às 18 UTC desde um dia antes a um após ao alagamento registrado em Itajubá em 02 janeiro de 2000. As figuras (d-f) foram obtidas em https://www.ncdc.noaa.gov/gibbs/year. Nas figuras, a letra B indica centro de baixa pressão, A centro de alta pressão, ASAS Anticiclone Subtropical do Atlântico Sul e a linha preta com triângulos a posição de um sistema frontal.

Com relação à circulação atmosférica em $250 \mathrm{hPa}$, nos três dias em estudo, a $A B$ tem seu centro deslocado para oeste, em relação a sua posição climatológica (Fig. 9a-c). Comparado a AB no caso de 1991, a de 2000 se estende para latitudes mais austrais e os ventos do seu setor sudeste estão associados a um cavado mais amplificado entre o Rio Grande do Sul e oceano Atlântico no dia prévio ao evento de inundação. A crista entre a região sudeste e o oceano também está bem configurada durante o período de estudo de 2000 . Já o VCAN, que aparecia com centro bem circular em 1991 e com padrão de 
nebulosidade como descrito em estudos clássicos como os de Kousky e Gan (1981) e Gan e Kousky (1986), em 2000 aparece mais amplificado meridionalmente, característica mostrada tanto nas imagens de satélite (Fig. 8d-f) quanto nas de circulação em 250 hPa (Fig. 9d-f).

No dia da inundação foi registrado no sul de Minas Gerais e em grande parte do Estado de São Paulo um total diário de precipitação superior a $50 \mathrm{~mm}$ (Fig. 7b). Nesse dia, o JBN continua bem configurado, assim como a região com menor radiação de onda longa (Fig. 9b), e os padrões atmosféricos em $250 \mathrm{hPa}$ (Fig. 9e). Um dia após o evento, ainda há elevados totais de precipitação no sul de Minas Gerais e presença bem marcada do JBN e do ciclone no oceano Atlântico (Fig. 7c).

Sugere-se que o alagamento e inundação ocorridos em Itajubá em janeiro de 2000 tenham sido decorrentes mais pelo volume de precipitação do que pela influência do solo encharcado, pois, como mostra a Figura $7 d-e$, a umidade relativa da camada entre 10 e $100 \mathrm{~cm}$ de profundidade era de $60 \%$; portanto, não estava saturada. Isso é outro diferencial em relação ao ano de 1991 , em que a umidade relativa da camada era cerca de $100 \%$.
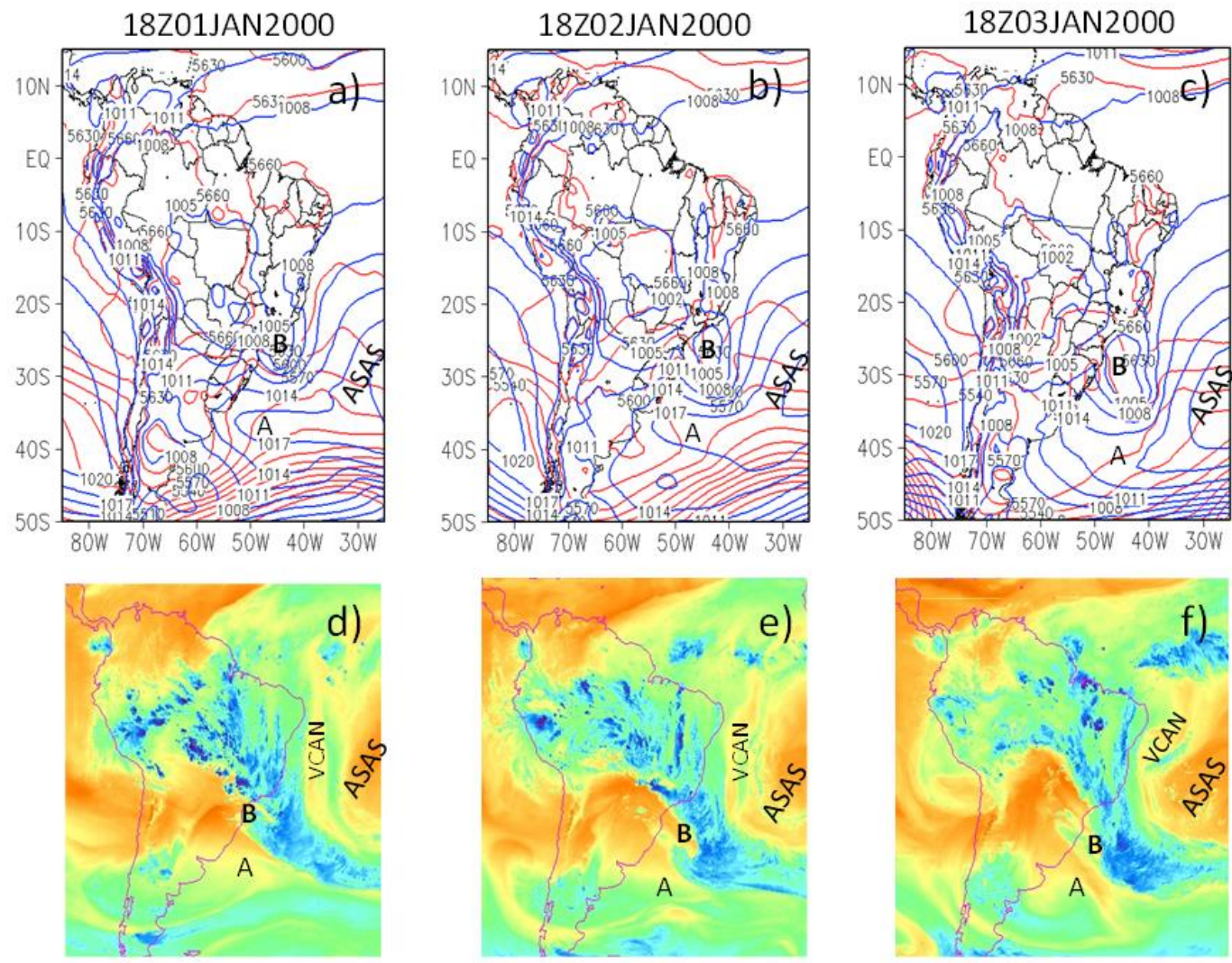

Figura 8 - (a-c) Pressão ao nível médio do mar ( $\mathrm{hPa}$, linha azul) e espessura da camada $500 / 1000 \mathrm{hPa}$ (metros, linha vermelha) e (d-f) vapor d'água na atmosfera (cores tendendo ao azul indicam maior quantidade de vapor d'água). Todas as figuras correspondem às 18 UTC desde um dia antes até um dia após o alagamento registrado em Itajubá em 02 janeiro de 2000. As figuras ( $d-f$ ) foram obtidas em https://www.ncdc.noaa.gov/gibbs/year. Nas figuras, a letra B indica centro de baixa pressão, A centro de alta pressão, ASAS Anticiclone Subtropical do Atlântico Sul e VCAN Vórtice Ciclônico de Altos Níveis nas Cercanias do Nordeste do Brasil. 

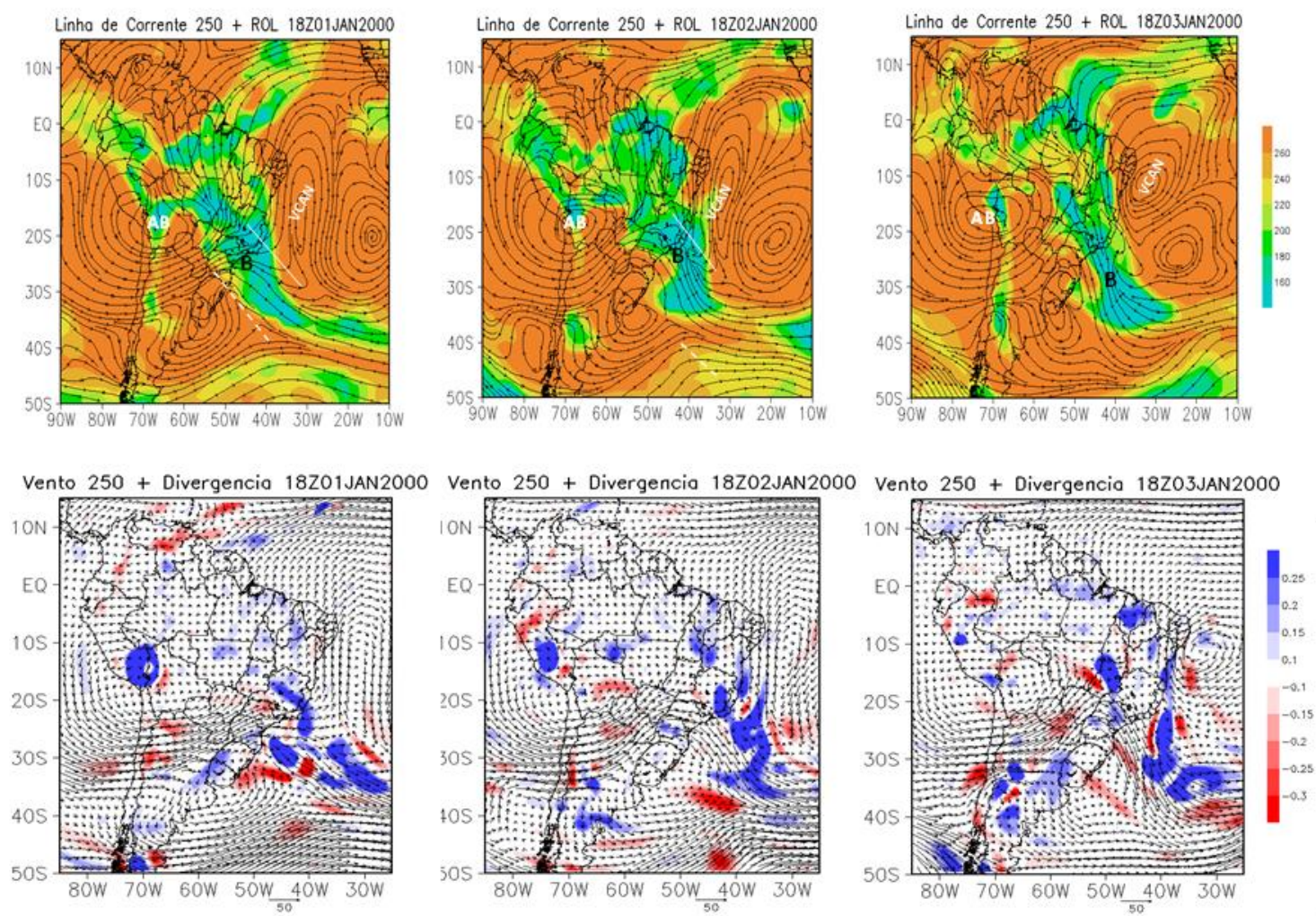

Figura 9 - (a-c) Radiação de onda longa (W/m2, colorido) e linhas de corrente em 250 $\mathrm{hPa}$ e (d-f) direção e intensidade do vento em $250 \mathrm{hPa}$ (setas) e divergência de massa em $250 \mathrm{hPa}$ (10-5s-1, colorido). Todas as figuras correspondem às 18 UTC desde um dia antes até um dia após o alagamento registrado em Itajubá em 02 janeiro de 2000. Nas figuras, a letra $B$ indica centro de baixa pressão em superfície. Já os demais símbolos indicam padrões em altos níveis sendo AB Alta da Bolívia, VCAN Vórtice Ciclônico de Altos Níveis nas Cercanias do Nordeste do Brasil, a linha branca tracejada indica o eixo de um cavado e a linha branca contínua indica o eixo de uma crista.

\section{CONCLUSÃO}

Esse estudo teve como objetivo descrever as características da atmosfera que propiciaram precipitação e que, consequentemente, favoreceram inundações e alagamentos na cidade de Itajubá, MG, em 16 de janeiro de 1991 e em 02 de janeiro de 2000, bem como destacar possíveis diferenças entre os dois casos.

De forma geral, a precipitação nos dois eventos estudados foi decorrente de episódio de ZCAS em que a ocorrência concomitante de diferentes sistemas atmosféricos contribuiu para a formação desta. Os sistemas em baixos níveis da atmosfera são: JBN se dirigindo da Amazônia para o sudeste do Brasil, escoamento do setor oeste do ASAS em direção ao sudeste do país, convecção local e centro de baixa pressão entre a costa sul-sudeste do Brasil. Já os sistemas em altos níveis da atmosfera são: a $A B$, o cavado em altos níveis nas cercanias do nordeste do Brasil com ou sem VCAN, uma crista entre o sudeste do Brasil e o oceano Atlântico e um cavado com eixo próximo ao sul do Brasil. 
Esses sistemas são ilustrados na Figura 10. Entretanto, a posição dos sistemas atmosféricos não foi exatamente igual nos dois eventos estudados. No evento de 1991, a área de baixa pressão entre a costa sul-sudeste do Brasil e o oceano Atlântico Sul não possuía linhas de mesma pressão fechadas, enquanto que em 2000 possuía. No evento de 1991 uma zona frontal no dia após a inundação interage com a atividade convectiva da ZCAS, o que não ocorre em 2000. Nesse mesmo ano, o ASAS cerca o sul do ciclone que está na costa sul-sudeste do Brasil, dificultando seu deslocamento. Em 1991, o centro da AB está na sua posição climatológica enquanto que em 2000 está deslocado para oeste. Além disso, em 2000, a AB se expande por latitudes mais austrais e também contribui para a formação de um cavado mais amplificado no sul do Brasil no dia anterior à inundação. Com relação ao VCAN, esse é mais alongado meridionalmente do que em 1991. Com base no exposto, as características da atmosfera no evento de 2000 foram similares às descritas por Escobar (2014) como as que mais geram episódios de chuvas anômalas em Minas Gerais. Já as de 1991 são mais similares com o padrão climatológico de verão.

Por fim, menciona-se que no evento de 1991 o alagamento e a inundação em Itajubá foram decorrentes do acúmulo de precipitação associada ao episódio de ZCAS, o que contribuiu tanto para um excesso de água no solo quanto para o extravasamento do rio Sapucaí, já que este e seus afluentes também receberam muita precipitação no período mencionado. Já no caso de 2000, o alagamento e a inundação podem ter ocorrido mais pelo volume de precipitação do que pela influência do solo saturado de água. Entretanto, ainda são necessários estudos adicionais sobre a umidade relativa do solo durante os eventos avaliados aqui. 


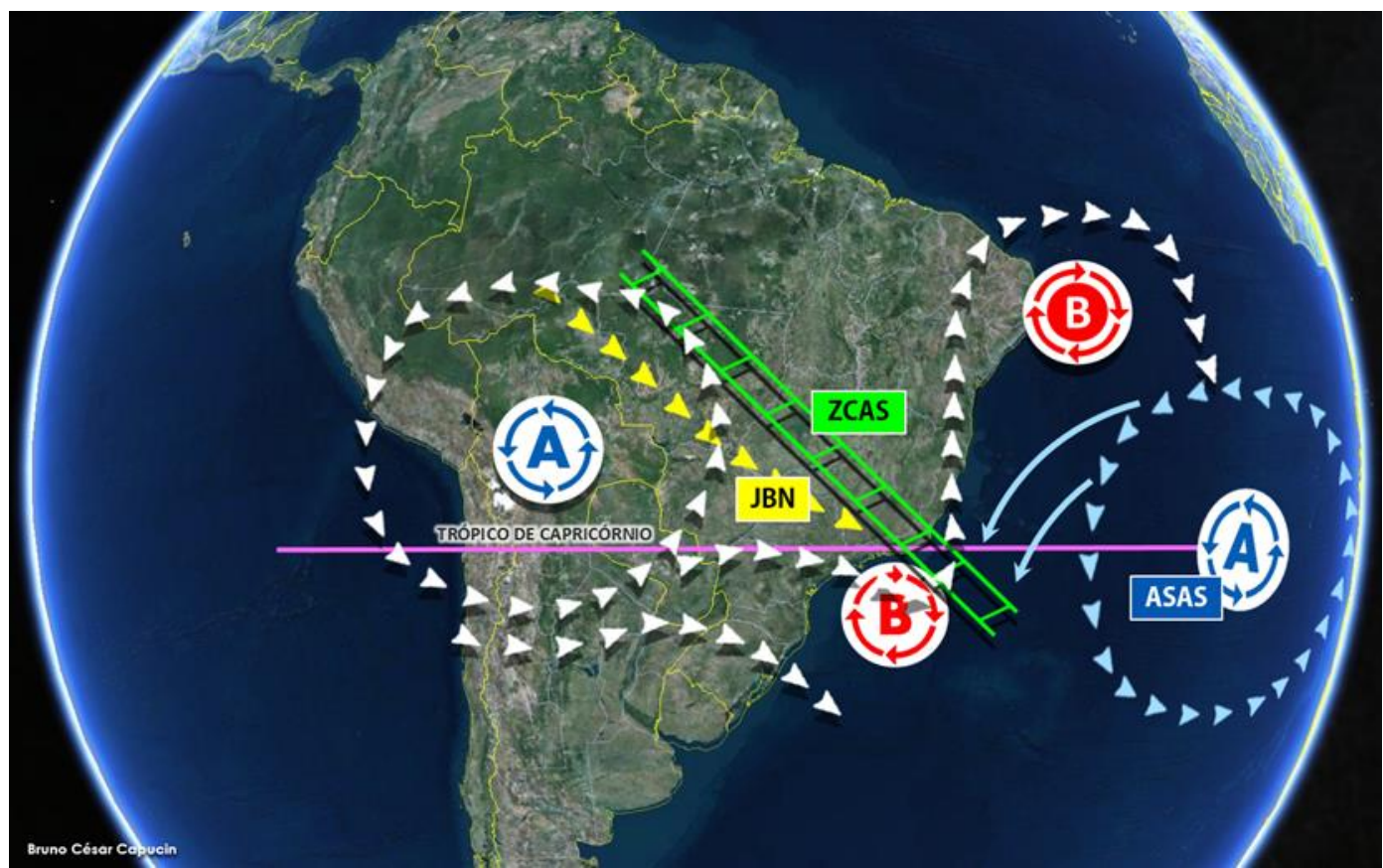

Figura 10 - Modelo conceitual da localização dos sistemas atmosféricos que contribuem para a formação da ZCAS e elevados totais de precipitação no sul de Minas Gerais. As setas brancas indicam a posição dos sistemas em altos níveis da atmosfera: sobre a Bolívia encontra-se a Alta da Bolívia (A) e nas cercanias do Nordeste do Brasil há um cavado com um Vórtice Ciclônico de Altos Níveis (VCAN) no seu centro (indicado com a letra B). As setas amarelas indicam a localização do Jato de Baixos Níveis (JBN) a leste dos Andes; as linhas verdes, a posição da Zona de Convergência do Atlântico Sul (ZCAS); as setas azuis, o Anticiclone do Atlântico Sul (ASAS) e, por fim, a letra B na costa sulsudeste do Brasil, uma região de baixa pressão. A arte gráfica da figura foi realizada por Bruno César Capucin especialmente para esse estudo.

\section{AGRADECIMENTOS}

Os autores agradecem ao CPC e ao ECMWF pela disponibilização dos dados utilizados neste trabalho, a NOAA e ao Latin America Flood and Drought Monitor pelas imagens de satélite e de umidade relativa do solo, respectivamente, e ao suporte da FAPEMIG e CNPq para a realização do estudo

\section{REFERÊNCIAS BIBLIOGRÁFICAS}

AMARAL, R.; GUTJAHR, M. R. Cadernos de Educação Ambiental (no 8): Desastres Naturais. Governo do Estado de São Paulo, Secretaria do Meio Ambiente, Instituto Geológico, 2012.

BARBosA, A. A.; OliveirA, G. M.; OLIVEIRA, T. J. Histórico de Enchentes em Itajubá/MG. Revista Meio Ambiente e Sustentabilidade, v. 9, n. 4, 2015.

CAMPETELLA, C. M.; VERA, C. S. The influence of the Andes Mountains on the South American low-level flow. Geophysical Research Letters, v. 29, n. 17, 7-1 a 7-4, doi: 10.1029/2002GL015451, 2002. 
CARVALHO, L. M. V; JONES, C.; LIEBMANN, B. The South Atlantic convergence zone: Intensity, form, persistence, and relationships with intraseasonal to interannual activity and extreme rainfall. Journal of Climate, v. 17, p. 88-108, 2004.

CHEN, M.; SHI, W.; XIE, P.; SILVA, V. B. S.; KOUSKY, V. E.; HIGGINS, R. W.; JANOWIAK, J. E. Assessing objective techniques for gauge-based analyses of global daily precipitation. Journal of Geophysical Research, v. 113, D04110, doi:10.1029/2007JD009132, 2008.

DEE, D. P; UPPALA, S. M.; SIMMONS, A. J. et al. The ERA-Interim reanalysis: configuration and performance of the data assimilation system. Quarterly Journal of the Royal Meteorological Society, v. 137, p. 553-597, 2011.

ESCOBAR, G. C. J. Padrões de circulação em superfície e em 500 hPa na América do Sul e eventos de anomalias positivas de precipitação no Estado de Minas Gerais durante o mês de dezembro de 2011. Revista Brasileira de Meteorologia, v. 29, n. 1, p. 105 - 124, 2014.

GAN, M. A.; KOUSKY, V. E. Vórtices ciclônicos da alta troposfera no Oceano Atlântico Sul. Revista Brasileira de Meteorologia, v. 1, p. 19-28, 1986.

GOOGLE MAPS. Disponível em: <https://www.google.com.br/maps>. Acesso em 20 de abril de 2016.

HOLTON, J. R. An Introduction to Dynamic Meteorology. 4ed, Elsevier, Seattle, 2004.

IPCC, 2007. Climate change 2007: The physical science basis. Contribution of Working Group I to the Fourth Assessment Report of the Intergovernmental Panel on Climate Change (S. Solomon, D. Qin, M. Manning, Z. Chen, M. Marquis, K. B. Averyt, M. Tignor and H. L. Miller, Eds.). Cambridge University Press, Cambridge, United Kingdom and New York, 996 pp.

IPCC, 2013. Climate change 2013: The physical science basis. Contribution of Working Group I to the Fifth Assessment Report of the Intergovernmental Panel on Climate Change (T. F. Stocker, D. Qin, G.-K. Plattner, M. Tignor, S. K. Allen, J. Boschung, A. Nauels, Y. Xia, V. Bex and P. M. Midgley, Eds.). Cambridge University Press, Cambridge, United Kingdom and New York, NY, USA, 1535 pp.

KALNAY, E.; KANAMITSU, M.; KISTLER, R.; COLLINS, W.; DEAVEN, D.; GANDIN, L.; IREDELL, M.; SAHA, S.; WHITE, G.; WOOLLEN, J.; ZHU, Y.; LEETMAA, A.; REYNOLDS, R.; CHELLIAH, M.; EBISUZAKI, W.; HIGGINS, W.; JANOWIAK, J.; MO, K. C.; ROPELEWSKI, C.; WANG, J; JENNE, R.; JOSEPH; D. The NCEP/NCAR 40-year reanalysis Project. Bulletin of the American Meteorological Society, $\mathrm{V}$. 77, n. 3, p. 437-471, 1996.

KNAPP, K. R.; ANSARI, S.; BAIN, C. L.; BOURASSA, M. A.; DICKINSON, M. J.; FUNK, C.; HELMS, C. N.; HENNON, C. C.; HOLMES, C. D.; HUFFMAN, G. J.; KOSSIN, J. P.; LEE, H.-T.; LOEW, A.; MAGNUSDOTTIR, G. Globally gridded satellite (GridSat) observations for climate studies. Bulletin of the American Meteorological Society, v. 92, p. 893-907, 2011.

KOUSKY, V. E. Pentad outgoing longwave radiation climatology for the South American sector. Revista Brasileira de Meteorologia, v. 3, p. 217-231, 1988. 
KOUSKY, V. E.; GAN, M. A. Upper tropospheric cyclonic vortices in the tropical South Atlantic. Tellus, v. 36, p. 538-551, 1981.

LIMA, K. C.; SATYAMURTY, P.; FERNÁNDEZ, J. P. R. Large-scale atmospheric conditions associated with heavy rainfall episodes in southeast Brazil. Theoretical and Applied Climatology, v. 101, n. 1- 2, p. 121-135, 2010.

MAIA, J. L. Estabelecimento de Vazões de Outorga na Bacia Hidrográfica do Alto Sapucaí, com a Utilização de Sazonalidade. Dissertação de Mestrado em Engenharia de Energia. Universidade Federal de Itajubá, 2003. Disponível em http://www.professoralexandre.unifei.edu.br/Mestrado/James.pdf $>$. Acesso em: 04 de julho de 2016.

MARENGO, J. A.; LIEBMANN, B.; GRIMM, A. M.; MISRA, V.; SILVA DIAS, P. L.; CAVALCANTI, I. F. A.; CARVALHO, L. M. V.; BERBERY, E. H.; AMBRIZZI, T.; VERA, C. S.; SAULO, A. C.; NOGUES-PAEGLE, J.; ZIPSER, E.; SETH, A. ; ALVES, L. M. Review recent developments on the South American monsoon system. International Journal of Climatology, v. 32, n. 1, p. 1-21, 2012.

MARENGO, J. A.; SOARES, W. R.; SAULO, C.; NICOLINI, M. Climatology of the Low-Level Jet East of the Andes as Derived from NCEP-NCAR Reanalyses: Characteristics and Temporal Variability. Journal of Climate, v. 17, n. 12, p. 2261-2280, 2004.

NOGUÉS-PAEGLE, J.; MO, K. C. Alternating wet and dry conditions over South America during summer. Monthly Weather Review, 125, p. 279-291, 1997.

NOGUÉS-PAEGLE， J.; PAEGLE, J.; DOUGLAS, M.; NICOLINI, M.; VERA, C.; MARENGO, J.; GARREAUD, R.; SHUTTLEWORTH, J.; MECHOSO, C. R.; BERBERY, E. H. American Low Level Jets: A Scientific Prospects and Implementation Plan. 2001.

OLIVEIRA, A. S. Interações entre sistemas frontais na América do Sul e convecção na Amazônia. INPE-4008-TDL/239, Dissertação de Mestrado em Meteorologia, Instituto Nacional de Pesquisas Espaciais, São José dos Campos, 1986.

REBOITA, M. S.; CORRÊA, M. P.; RODRIGUES, M.; SILVA, J. P. R. Um balanço do curso de ciências atmosféricas no sul de Minas Gerais: ensino, pesquisa, extensão e benefícios à sociedade. Revista Brasileira de Geografia Física, v. 09, n. 07, 2312-2324, 2016.

REBOITA, M. S; GAN, M. A; ROCHA, R. P; AMBRIZZI, T. Regimes de precipitação na América do Sul: uma revisão bibliográfica. Revista Brasileira de Meteorologia, v. 25, n. 2, p. 185-204, 2010.

REBOITA, M. S.; KRUSCHE, N.; AMBRIZZI, T.; ROCHA, R. P. Entendendo o Tempo e o Clima na América do Sul. TerraE Didática, v. 8, n. 1, p. 34-50, 2012a.

REBOITA, M. S.; DA ROCHA, R. P.; AMBRIZZI, T. Dynamic and Climatological Features of Cyclonic Developments over Southwestern South Atlantic Ocean. In: B. Veress; J. Szigethy. (Org.). Horizonts in Earth Science Research, v. 6, p. 135$160,2012 b$. 
REBOITA, M. S.; SOUZA, D. C.; RAMALHO, V. Water Balance and Aridity Index in Itajubá. In: V Simpósio Internacional de Climatologia, 2013, Florianópolis. Interação Oceano Atmosfera: Impactos Climáticos no Presente e Cenários Futuros.

RELATÓRIO TÉCNICO. Relatório da Comissão de Avaliação Técnica para Recuperação e Urbanização das Margens do Rio Sapucaí e seus afluentes da Área Urbana. Universidade Federal de Itajubá (UNIFEI). 2000. Disponível em < http://www.professoralexandre.unifei.edu.br/Arquivos/Rio_Sapucai2000.pdf>. Acesso em 04 de julho de 2016.

SACRAMENTO-NETO, O. B.; ESCOBAR, G. C. J.; SILVA, P. E. D. Método objetivo para identificar episódios de Zonas de Convergência de Umidade (ZCOU) no ambiente operacional do Centro de Previsão de Tempo e Estados Climáticos CPTEC. In XVI Congresso Brasileiro de Meteorologia, São Paulo, 2010. Disponível em <http://www.sbmet.org.br/cbmet2010/artigos/695_86757.pdf>. Acesso em 20 de maio de 2016.

SANTOS, F. L. Conflito da ocupação urbana de Itajubá/MG com base na legislação municipal usando SIG. Dissertação de Mestrado em Meio Ambiente e Recursos Hídricos. Universidade Federal de Itajubá, 2013. Disponível em <https://saturno.unifei.edu.br/bim/0041963.pdf>. Acesso em: 27 de julho de 2017.

SELUCHI, M. E.; CHOU, S. C. Synoptic patterns associated with landslide events in the Serra do Mar, Brazil. Theoretical and Applied Climatology, v. 98, p. 67-77, 2009.

SUGAHARA, S.; DA SILVEIRA, R. B; DA ROCHA, R. P. Estimativa da probabilidade do evento extremo de precipitação de janeiro de 2000 no Vale do Paraíba, baseada na distribuição generalizada de Pareto. Revista Brasileira de Geofísica, v. 28, n. 2, p. 193-208, 2010.

SILVA, E. D.; REBOITA, M. S. Estudo da Precipitação no Estado de Minas Gerais - MG. Revista Brasileira de Climatologia, v. 13, p. 120-136, 2013.

SILVA, V. B. S.; KOUSKY, V. E.; SHI, W.; HIGGINS, W. An Improved Gridded Historical Daily Precipitation Analysis for Brazil. Journal of Hydrometeorology, $v$. 8, p. 847-861, 2007.

SILVA, V. B. S.; KOUSKY, V. E.; HIGGINS, W. Daily Precipitation Statistics for South America: An Intercomparison between NCEP Reanalyses and Observations. Journal of Hydrometeorology, v. 12, p. 101-117, 2011.

VERA,C.; HIGGINS, W.; J. AMADOR, J.; AMBRIZZI, T.; GARREAUD, R.; GOCHIS, D.; GUTZLER, D.; LETTENMAIER, D.; MARENGO, J.; MECHOSO, C. R.; NOGUESPAEGLE, J.; SILVA DIAS, P. L.; ZHANG, C. Toward a unified view of the American monsoon systems. Journal of Climate, v. 19, n. 20, p. 4977-5000, 2006.

WALLACE, J. M.; HOBBS, P. V. Atmospheric science: an introductory survey. 2nd ed., International Geophysics Series, Academic Press, 2006.

ZHOU, J.; LAU, K. M. Does a monsoon climate exists over South America? Journal of Climate, v. 11, p. 1020-1040, 1998. 